\title{
1 Molecular diversity of Rice grassy stunt virus in Vietnam
}

Ta Hoang-Anh ${ }^{1}$, Nguyen Doan-Phuong ${ }^{1}$, Causse Sandrine ${ }^{3}$, Nguyen Thanh-Duc ${ }^{2,3}$, Ngo Vinh-Vien ${ }^{1}$, Hébrard Eugénie ${ }^{3}$

${ }^{1}$ Plant Protection Research Institute (PPRI) - Hanoi, Vietnam

${ }^{2}$ Agricultural Genetics Institute (AGI) - Hanoi, Vietnam

${ }^{3}$ UMR Résistance des Plantes aux Bioagresseurs, Institut de Recherche pour le Développement (IRD) Montpellier, France

\section{ABSTRACT}

Rice grassy stunt virus (RGSV, Tenuivirus) recently emerged on rice in Vietnam, causing high yield losses during 2006-2009. The genetic diversity of RGSV is poorly documented. In this study, the two genes encoded by each ambisense segment RNA3 and RNA5 of RGSV isolates from 6 provinces of South Vietnam were sequenced. P3 and Pc3 (RNA3) have unknown function, P5 (RNA5) encodes the putative silencing suppressor and Pc5 (RNA5) encodes the nucleocapsid protein $(\mathrm{N})$. The sequences of 17 Vietnamese isolates were compared to reference isolates from North and South Philippines. The average nucleotide diversity among the isolates was low. We confirmed a higher variability of RNA3 than RNA5 and Pc3 than P3. No relationships between the genetic diversity and the geographic distribution of RGSV isolates could be ascertained, likely because of the long-distance migration of the insect vector. This data will contribute to a better understanding on the RGSV epidemiology in South Vietnam, a prerequisite for further management of the disease and rice breeding for resistance.

\section{TEXT}

In contrast to Rice stripe virus (RSV) that remains one of the main destructive rice pathogen in East Asia (Wei et al., 2009), Rice grassy stunt virus (RGSV) had shown a low incidence since mid-eighties. However, severe epidemics of RGSV occurred during 2006-2009 in the Mekong Delta provinces in Vietnam. Infected rice plants show typical symptoms with stunting and proliferation of thin tillers with erected growing habit. RGSV induces incomplete flowering and unfilled grains. Faced to high losses up to 700,000 tons of rice, exportations were temporally stopped by the end of 2006 Spring crop (Vien et al., 2007). The RGSV emergence in Vietnam has a multifactorial origin. Outbreaks of the insect vector, incorrect use of pesticides and continuous cultivation of rice have been identified as factors of emergence. However, the role of viral factors has not been investigated.

Tenuiviruses are complex in nature and remain poorly understood. They have some similarities with viruses classified in the family Bunyaviridae. They are transmitted in a propagative manner by a particular species of planthoppers to plants of the family Poaceae. RGSV is transmitted to rice by Nilaparvata lugens. Tenuiviruses are characterized by a thread-like morphology and a large segmented genome of 17-26 kb (Shirako et al., 2011). The number of viral genomic segments varies from 4 to 6 and they were named according to their size. They have an ambisense coding strategy. The RdRp polymerase is encoded by the viral complementary sense (vc) of RNA1, the largest molecule. The nucleocapsid $(\mathrm{N})$ is encoded by vcRNA3 and the major non-capsid protein $(\mathrm{NCP})$ that accumulates in infected plants is encoded by vRNA4 (Liang et al., 2005). A silencing suppressor (NS3) is encoded by vRNA3. High amounts of RSV NS3 transcripts were found in viruliferous insects (Zhang et al., 2010). RGSV is the unique tenuivirus that contains 6 RNA segments. RNAs 5 and 6 of 
RGSV correspond to RNAs 3 and 4 of other tenuiviruses but are distantly related (Toriyama et al., 1997). Based on the phylogenetic analysis of these fragments, RGSV is the most basal species compared to the other members of the genus. Sequences of RGSV RNA3 and RNA4 are orphans in the public databases, the functions of the genes are still unknown.

The knowledge about genetic diversity of tenuiviruses was previously restricted to pairwise comparison of isolates from distinct geographical origins (de Miranda et al., 1997, Mahmoud et al., 2007). Recently, the phylogenetic analyses of larger samples from Korea and China confirmed the low diversity of RSV RNA1-4 (Jonson et al., 2009a, Jonson et al., 2009b, Wei et al., 2009). The molecular diversity of RGSV is poorly documented. Up to now, only two complete genomic sequences from North and South Philippines have been published (Miranda et al., 2000). Although RNA1, 4 and 5 were very similar for the two isolates, RNA2, 3 and 6 diverged more.

In this study, we assessed the genetic diversity of RGSV in 6 provinces of South Vietnam. Samples collection was made at end of May 2009 and in October 2011 in diseased fields of Binh Thuan province (South-Est Vietnam) and 5 provinces of the Mekong Delta (Supp. Table S1). Leaves with typical symptoms of RGSV were dried with silica gel at room temperature and stored at $-20^{\circ} \mathrm{C}$. The RNA extraction and purification were performed with Trizol according to the manufacturer's instructions. After quantification, 0.5 to $1.5 \mu \mathrm{g}$ of total RNA was used in one-step RT-PCR as previously described (Anh et al., 2009). Primer pairs were designed to amplify four RGSV genes located on two segments (Supp. Table S2). We focused on the unknown P3 and Pc3, the putative silencing suppressor P5 and the nucleocapsid protein ( $\mathrm{N}$ or Pc5). The fragments encoding P3, Pc3 and P5 were amplified using Taq-DNA polymerase and Reverse transcriptase enzymes (Fermentas). The Pc5 fragment was amplified using one-step RT-PCR kit (Qiagen) following the manufacturer's instructions. The PCR products were sequenced in both senses. When double pics were detected in the electropherograms, a cloning step was performed using the pGEM-T vector kit. The sequences were deposited in EMBL Nucleotide Sequence Database (Accessions HE963224 to HE963291). The sequences obtained in this study were aligned with the Philippines isolates using ClustalW with default parameters (Thompson et al., 1994). The diversity index $(\pi)$, which is the average number of nucleotide differences per site between two sequences was calculated for each gene. Additionally, $\pi_{\mathrm{a}}$, the average number of nucleotide substitutions per nonsynonymous site, $\pi_{\mathrm{s}}$, the average number of nucleotide substitutions per synonymous site, and their ratio $\left(\omega=\pi_{\mathrm{a}} / \pi_{\mathrm{s}}\right)$ were calculated. All diversity indices were calculated by using DNAsp version 5.10 (Librado \& Rozas, 2009). The sequences were compared in a phylogenic tree including the two reference isolates from Philippines. Phylogenetic relationships between the isolates were determined by a distance method where the nucleotide pairwise distances were corrected by using the Kimura twoparameter methods and trees were reconstructed by the Neighbour-Joining (NJ) method with MEGA 5 (Tamura et al., 2011). The significance of the internal branches was evaluated by using 1,000 bootstrap replications.

We obtained the sequences of P3, Pc3, P5 and Pc5 from 17 RGSV isolates. The average nucleotide diversity among the isolates was $1.9 \%$ (Table 1). The average variation in synonymous sites ranged from 2.8 to $6.6 \%$. The nonsynonymous diversity ( $\pi \mathrm{a}$ ) was much less than the synonymous diversity and ranged between 0.1 and $3.2 \%$. Nucleotide diversity was variable among the genes. P3 and Pc3 were the most variable, whereas P5 and Pc5 were the most conserved. In both segments, the genes encoded by the viral complementary sense 
(Pc3 and Pc5) were more variable than the viral sense (P3 and P5). The low variability in the four genes illustrated the extent of the genomic constraints.

The general topology of the phylogenetic trees was different depending on the RNA segment but was similar for both genes from the same segment. Based on P5 and Pc5 sequences, all isolates from Vietnam were clustered into one clade while the two Philippines isolates grouped in another clade (data not shown). Due to a low number of informative sites, the resolution of the phylogenetic tree was low. Based on P3 and Pc3 sequences, the isolates were clustered into 3 clades. The isolate Cotabato from Philippines stood alone, a second clade contained the isolate Laguna from Philippines and four Vietnamese isolates, and most of the other isolates were grouped in the third clade divided into two sub-groups (Figure 1). The factors involved in this clustering could not be ascertained. No relationships between the genetic diversity and the geographic distribution of RGSV isolates were detected based on RNA3. Isolates collected in the same province belonged to two different clades whereas isolates from distant areas clustered in the same clade. While the two Philippines isolates originated from locations which were about $800 \mathrm{~km}$ apart, the Laguna isolate and several Vietnamese isolates distant from $1700 \mathrm{~km}$, belonged to the same clade. In this clade, the isolates were collected in two Mekong Delta provinces (Tien Giang and Kien Giang) far from $150 \mathrm{~km}$. However, several isolates collected in these two provinces clustered into the other clade with isolates from Binh Thuan in South-East Vietnam. All isolates collected from different sites in Binh Thuan provinces, which are $20 \mathrm{~km}$ apart from each other, were clustered in different sub-clades (Figure 1). No spatial structuration of the RGSV genetic diversity was revealed likely because of the migration of the brown planthopper (BPH) Nivaparlata lugens, the insect vector of RGSV. The BPH ability to migrate for long distances between countries in South Asia has been previously demonstrated (Otuka, 2009). In Vietnam, BPHs should transmit different isolates between different geographic locations among the Mekong Delta provinces and between Mekong Delta and the mountainous areas of Binh Thuan province.

This study was the first analysis on the genetic diversity of RGSV. Our data will contribute to a better understanding of the epidemiology in South Vietnam, a prerequisite for further management of the disease and rice breeding for resistance. For instance, the confirmation of the low diversity of P5, the silencing suppressor, is very promising for future transgenic strategies. In future, the genetic diversity of RGSV will be considered at a regional scale including the neighbouring countries of Vietnam. Several cases of RGSV were recently suspected in Thailand (Ta H.A., personal communication). In addition to RNA3, the genetic analysis would include other variable segments such as RNA2 and RNA6.

This work was supported by a BEST grant from Département de Soutien et Formation (DSF IRD), a bilateral project funded by Ministry of Science and Technology of Vietnam and Ministère des Affaires Etrangères de la France (PHC Hoa Sen Lotus 23968UL) and a project from Groupement de Recherche International (GDRI BMI CNRS/IRD).

\section{Figure legend:}

Figure 1. Phylogenetic trees of 17 isolates of RGSV calculated from the P3 (a) and from the Pc3 sequences (b). These trees were constructed by using the Neighbor-Joining method. The stars indicate the nodes with bootstrap values $>80 \%$. The geographic origins are indicated by 
the name of the isolates: BT, Binh Thuan; TG, Tien Giang; LA, Long An; KG, Kien Giang; HG, Hau Giang; CT, Can Tho; Ph, Philippines.

\section{References:}

Anh, T. H., Vien, N. V., Anh, N. T., Huyen, T. T. T., Chung, N. V. \& Phuong, N. D. (2009). One-step RT-PCR for detection of rice grassy stunt and rice ragged stunt viruses. $J$. Plant Protection (in Vietnamese) 5, 21-26.

de Miranda, J. R., Ramirez, B. C., Munoz, M., Lozano, I., Wu, R., Haenni, A. L., Espinoza, A. M. \& Calvert, L. A. (1997). Comparison of Colombian and Costa Rican strains of rice hoja blanca tenuivirus. Virus Genes 15, 191-3.

Jonson, M. G., Choi, H. S., Kim, J. S., Choi, I. R. \& Kim, K. H. (2009a). Complete genome sequence of the RNAs 3 and 4 segments of Rice stripe virus isolates in Korea and their phylogenetic relationships with Japan and China isolates. Plant Pathol. J. 25, 142-150.

Jonson, M. G., Choi, H. S., Kim, J. S., Choi, I. R. \& Kim, K. H. (2009b). Sequence and phylogenetic analysis of the RNA1 and RNA2 segments of Korean Rice stripe virus isolates and comparison with those of China and Japan. Arch Virol 154, 1705-8.

Liang, D., Qu, Z., Ma, X. \& Hull, R. (2005). Detection and localization of Rice stripe virus gene products in vivo. Virus Genes 31, 211-221.

Librado, P. \& Rozas, J. (2009). DnaSP v5: A software for comprehensive analysis of DNA polymorphism data. Bioinformatics 25, 1451-1452.

Mahmoud, A., Royer, M., Granier, M., Ammar, E. D. \& Peterschmitt, M. (2007). High genetic identity between RNA 3 segments of an Old World isolate and a New World isolate of Maize stripe virus. Arch Virol 152, 1583-6.

Miranda, G. J., Azzam, O. \& Shirako, Y. (2000). Comparison of nucleotide sequences between northern and southern philippine isolates of rice grassy stunt virus indicates occurrence of natural genetic reassortment. Virology 266, 26-32.

Otuka, A. (2009). Migration of rice planthoppers and simulation techniques. In Planthoppers: new threats to the sustainability of intensive rice production systems in Asia, pp. 343356. Edited by K. L. Heong \& B. Hardy. Los Banos (Philippines): International Rice Research Institute.

Shirako, Y., Falk, B. W. \& Haenni, A. L. (2011). Genus Tenuivirus. In Virus taxonomy: classification and nomenclature of viruses: Ninth Report of the International Committee on Taxonomy of Viruses., pp. 771-776. Edited by A. M. Q. King, E. J. Lefkowitz, M. J. Adams \& E. B. Carstens. San Diego: Elsevier Academic Press.

Tamura, K., Peterson, D., Peterson, N., Stecher, G., Nei, M. \& Kumar, S. (2011). MEGA5: Molecular Evolutionary Genetics Analysis using Maximum Likelihood, Evolutionary Distance, and Maximum Parsimony Methods. Molecular Biology and Evolution 28, 2731-2739.

Thompson, J. D., Higgins, D. G. \& Gibson, T. J. (1994). CLUSTAL W: improving the sensitivity of progressive multiple sequence alignment through sequence weighting, position-specific gap penalties and weight matrix choice. Nucleic Acids Res 22, 46734680.

Toriyama, S., Kimishima, T. \& Takahashi, M. (1997). The proteins encoded by rice grassy stunt virus RNA5 and RNA6 are only distantly related to the corresponding proteins of other members of the genus Tenuivirus. J Gen Virol 78 ( $\mathbf{P t ~ 9 ) , ~ 2 3 5 5 - 6 3 . ~}$

Vien, N. V., Lam, N. V., Thanh, T. T., Thanh, D. V., Cuong, N. N. \& Ta-Hoang, A. (2007). Study on Rice grassy stunt virus and Rice ragged stunt virus and their management. In Annual Report of PPRI (in Vietnamese). 
Wei, T. Y., Yang, J. G., Liao, F. R., Gao, F. L., Lu, L. M., Zhang, X. T., Li, F., Wu, Z. J., Lin, Q. Y., Xie, L. H. \& Lin, H. X. (2009). Genetic diversity and population structure of rice stripe virus in China. J Gen Virol 90, 1025-34.

Zhang, F., Guo, H., Zheng, H., Zhou, T., Zhou, Y., Wang, S., Fang, R., Qian, W. \& Chen, X. (2010). Massively parallel pyrosequencing-based transcriptome analyses of small brown planthopper (Laodelphax striatellus), a vector insect transmitting rice stripe virus (RSV). BMC Genomics 11, 303.

8

9 Table 1. Diversity indices (average) calculated on the total $(\pi)$, synonymous $(\pi \mathrm{s})$, and 10 nonsynonymous $(\pi \mathrm{a})$ sites and the ratio $(\omega=\pi \mathrm{a} / \pi \mathrm{s})$ for the four ORFs after alignment of the 11 RGSV sequences

12

\begin{tabular}{cccccccc}
\hline & \multicolumn{7}{c}{ Diversity index for: } \\
\cline { 2 - 6 } RGSV gene & \multicolumn{2}{c}{ Total sites } & \multicolumn{2}{c}{ Synonymous sites } & Nonsynonymous sites & & $\omega$ \\
\cline { 2 - 6 } & $\mathrm{Nb}$ & $\mathrm{Avr} \pi$ & $\mathrm{Nb}$ & Avr $\pi \mathrm{s}$ & $\mathrm{Nb}$ & Avr $\pi \mathrm{a}$ & \\
\hline P3 & 558 & 0.019 & 121 & 0.064 & 437 & 0.007 & 0.11 \\
Pc3 & 816 & 0.039 & 163 & 0.066 & 653 & 0.032 & 0.49 \\
P5 & 573 & 0.010 & 133 & 0.028 & 440 & 0.004 & 0.14 \\
Pc5 & 876 & 0.008 & 201 & 0.030 & 675 & 0.001 & 0.03 \\
\hline
\end{tabular}

13

14

15 
a

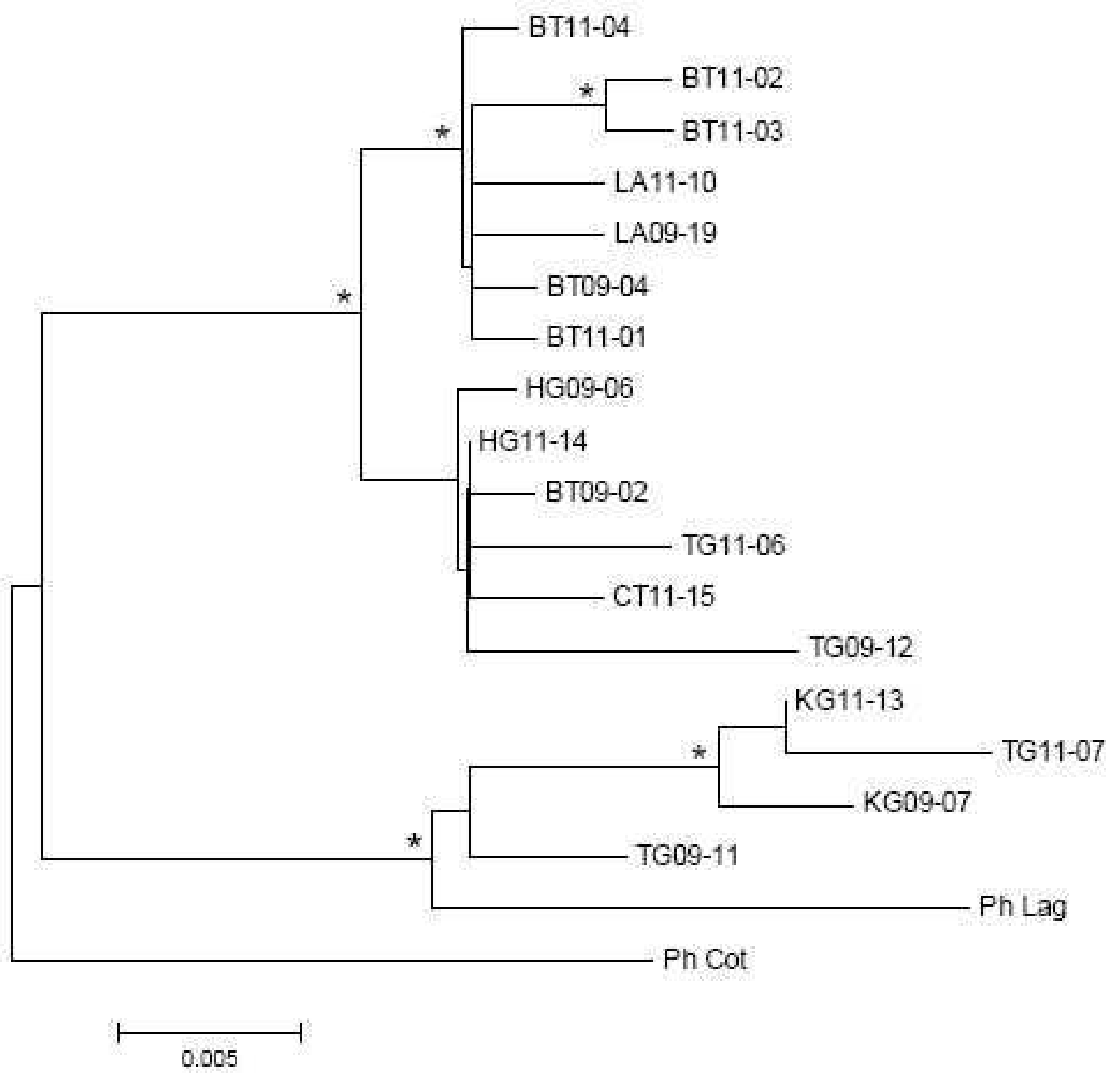

